\title{
Out-of-Home Mobility and Social Participation of Older People: a Photo-Based Ambulatory Assessment Study
}

\section{Daniela Kahlert ${ }^{1} \cdot$ Niklas Ehrhardt $^{2}$}

Received: 3 May 2019 / Accepted: 30 March 2020 / Published online: 19 April 2020

(C) The Author(s) 2020

\begin{abstract}
Research has shown that social participation contributes to older people's healthy ageing. Out-of-home mobility may promote higher levels of social participation among older people. However, mobility and social participation are sophisticated constructs. Social participation can be distinguished among different levels, such as being alone, being alone surrounded by others, interacting with others or engaging in activities together. Social participation and time spent in out-ofhome-mobility can be difficult to remember and therefore difficult to assess. Picture-based ambulatory assessment provides valid and reliable information about people's mobility as well as their level of participation with high ecological validity. The aim of the study was to investigate older people's level of social participation and its association with high or low out-of-home mobility. In sum, 23072 pictures (mean per person $=2307$; $\mathrm{SD}=686.7$ ) involving ten older people (mean age $=75.4$ years; $\mathrm{SD}=7.5$ years) living in southwestern Germany were analysed. They were asked to wear a wearable camera for two consecutive days. Images were automatically captured every 15 seconds. Image analysis shows that study participants spent most of their time alone (at approximately 35\% of analysed time). Out-of-home mobility was associated with higher levels of social participation, such as helping others $\left(\mathrm{chi}^{2}=200,664\right.$, df $\left.=5, p<.001\right)$. Picturebased ambulatory assessment can assist in the gathering of necessary sophisticated information that is difficult to assess via questionnaires or other similar methods.
\end{abstract}

Keywords Social participation · Out-of-home mobility · Older people · Ambulatory assessment $\cdot$ Photo-based study

Daniela Kahlert

daniela.kahlert@ph-gmuend.de

Niklas Ehrhardt

niklas.ehrhardt@ inspo.uni-stuttgart.de

Extended author information available on the last page of the article 


\section{Introduction}

In most European societies, the population is getting older. The German Scientific Advisory Council on Global Change (WBGU 2016) anticipates this community transformation as one of the greatest social challenges for politics and science. Getting older is often accompanied by psychological, physical or social changes. For instance, older people could feel more isolated because of the premature death of family members or friends (Lampinen and Heikkinen 2003). From a physiological perspective, getting older leads to a reduction in muscular mass (DiPietro 2001), which increases the risk of falls (Schott 2007) and may reduce older people's mobility. However, getting older is not associated with negative changes per se. Being physically active and out-of-home mobility promote people's health (Faß and Schlesinger 2019), autonomy, identity and well-being, even in older age (Claßen et al. 2014; Hamer et al. 2014; Oswald and Konopik 2015; Wahl et al. 2012). Active engagement, which includes active social participation and (active) mobility (Rowe and Kahn 1997), is an essential component of ageing well (Wahl et al. 2012), reduces premature mortality (Maier and Klumb 2005; Pynnönen et al. 2014; Thomas 2012) and morbidity (Hwang Han et al. 2017) and increases cognitive function (Miceli et al. 2018) and well-being (Bauman et al. 2016). In particular, being with others or belonging to groups (e.g., friends or organised groups, such as clubs) is positively associated with better health and health-related outcomes (Burholt et al. 2019; Tomaka et al. 2006). Social opportunities are needed to maintain social interactions and participation in later life (Scharlach 2017). The living environment might be crucial for older people's active engagement and mobility (e.g., Glass and McAtee 2006; Rowles and Bernard 2013; Sallis et al. 2006; Wahl et al. 2012), since it may offer more or fewer "opportunity structures" (Baum and Palmer 2002, p. 352; Macintyre and Ellaway 1999, p. 169), such as a place where individuals can meet each other. Environments may increase or decrease the likelihood of out-of-home mobility (Tomaszewski 2013) and, in turn, the likelihood of participating socially in the living environment (Annear et al. 2014; Richard et al. 2013; Schlicht 2017; Schlicht and Oswald 2018). An ageing-friendly living environment entails accessible and personally meaningful destinations. It pulls people out of their homes and enables them to participate actively in social or community affairs (Lewicka 2011; Rubinstein 1989; Tomaszewski 2013; Weideman and Anderson 1985).

Social participation has been used and defined in various ways (Piskur et al. 2014). One approach defines it as the involvement of people in decision-making processes, for instance, in communities or policy (Bathgate and Romios 2011). Moreover, social participation may refer to the number of contacts and interactions people have during the course of a day or week (Koster et al. 2009). Social network theories focus on the inter- and intra-relationships of group members (Putnam 2000). A further perspective sheds light on the extent to which people are involved in activities with others in a community (Levasseur et al. 2010). Based on different original definitions found in the literature published between 1980 and 2009, Levasseur et al. (2010) proposed a taxonomy of social activities that distinguishes among six distinct levels of social participation. These levels account for the individual proximity of involvement with others, the goal of the activity and whether the individual performs activities with others or not. Therefore, being alone is a level of social participation (level 1) lower 
than being alone but having others around (level 2). Interacting with others (social contact) without engaging in a specific activity with them (level 3) is considered a higher level of social participation than the two former activities, but it is regarded as lower than engaging in activities collaboratively (level 4), helping others (level 5) or contributing to society (level 6). This distinction not only reflects different concepts of (social) activities and social participation but also serves as an important theoretical background for health-related research. Due to the abovementioned contribution of social participation to ageing well, it is important to clarify what, in turn, contributes to spending more time engaging in higher levels of social participation.

Social participation is usually assessed by either interviews or questionnaires, which are sometimes combined within a study. For instance, people could be asked for the number of memberships in associations (e.g., sports, cultural or political; Buffel et al. 2013). The 'Elderly Activity Inventory Questionnaire (Lefrancois et al. 2001) and the 'Community Participation Scale' (Gracia and Herrero 2004) focus on the number of social activities people join (e.g., going to church or the theatre). Furthermore, counting the number of people or acquaintances seen as well as the number of phone calls or visits made during a typical week has been used to operationalise social participation (e.g., Hodge et al. 2013; Rosso et al. 2013).

According to Levasseur et al. (2010), social participation extends beyond the number of contacts or the attendance of social activities. Subjective self-report measures in interviews or questionnaires fail to distinguish among the six levels of social participation of the proposed taxonomy. Following Levasseur et al. (2010), participating in a social activity, such as a church visit, or travelling to a specific place could be practised alone and therefore classified as performed alone (level 1); such activities could also be performed with others around but without communication with them (level 2); these activities may also involve interaction with others (level 3) or serve as a joint activity (level 4); or activities may involve helping others (level 5) or contributing to society (level 6). Therefore, a further method is needed to assess relevant contextual information that may not always be remembered.

Physical mobility as well as life-space mobility (i.e., movement beyond one's town or geographic region) are most often assessed by self-report measures, such as reports of the distance moved during the previous 4 weeks (Baker et al. 2003). Travel diaries are another common method of assessing physical mobility, in which people record their travel behaviour for a given period of time at predetermined intervals (e.g., $12 \mathrm{~h}$ at 10-min intervals). Such measures can be burdensome and may lack validity due to problems in accurately remembering each minute of mobility as well as discrete activities throughout a day (Kelly et al. 2015; Takemoto et al. 2015).

Ambulatory assessment methods are technology-based and aim to gather information on on-going behaviour while individuals engage in their regular activities. The data are collected in real time and natural settings and therefore offer data with high reliability and high ecological validity (Schlicht et al. 2013; Trull and Ebner-Priemer 2013). Global positioning systems (GPS), for instance, have been applied for tracking mobility (Brusilovski et al. 2016). Wearable cameras capturing digital lifelog images are another way of applying ambulatory assessment methods. Devices such as the SenseCam or the Autographer are typically worn during the whole day on a lanyard around the neck and passively take pictures of an individual's life. Pictures are taken automatically at a pre-determined rate (e.g., $15 \mathrm{~s}$ ). Applying wearable cameras is a 
recent method to investigate travelling and health behaviour. One could also calculate the time spent engaged in those activities by increasing the capture rate of the camera (Kelly et al. 2014; Sawyer et al. 2018). Wearable cameras have been shown to be a suitable instrument to measure different kinds of physical activities (Kelly et al. 2011), as well as everyday activities (Wang and Smeaton 2013). Wearable cameras have also been used to investigate active mobility in different contexts. Doherty and colleagues studied the feasibility of wearable cameras in the categorisation of types of activity, such as bicycling or walking. Furthermore, they categorised the context of the activities as well, such as 'indoor', 'outdoor', 'transportation' or 'social/interaction' (Doherty et al. 2013c). Finally, using wearable cameras is a valuable approach to investigating variables from a first-person perspective. As such, Oliver et al. (2013) applied a picturebased assessment to audit the environmental features of active transport mobility, such as work-related cycling and walking routes.

The aim of the given study was to describe the amount of time older adults spend in out-of-home mobility as well as their level of social participation in their everyday lives. A further goal was to investigate whether the time spent at different levels of social participation was associated with high or low out-of-home mobility. Due to the sophisticated distinction of social participation into different levels and the challenge of assessing reliable data about such participation and people's out-of-home mobility, a picture-based ambulatory assessment was applied.

\section{Methods}

\section{Participants and Study Setting}

The inclusion criteria were a) being 65 years or older, b) having a current driver's licence, c) having no current employment relationship(s), d) having no current profound physical constraints influencing out-of-home mobility, and e) living in a rural area (defined by Regionalverband Nordschwarzwald 2007). The main reasons for the inclusion criteria were to control for some relevant moderator variables of out-of-home mobility, such as living in cities compared to rural areas (Tomaszewski 2013). Recruitment was consecutively performed in a municipality with approximately 8000 inhabitants located in the Black Forest in western Baden-Württemberg, Germany. The town has 20 clubs and facilities for the needs of daily living (e.g., grocery shops). The municipality is completely surrounded by forest and nature. The sample included 10 participants (male: 50\%; female: 50\%) between 67 and 85 years of age $\left(M_{\text {Age }}=75.4 \pm\right.$ 7.53 years old). These participants lived for 48 years $( \pm 28.1$ years $)$ in the same place in their private homes. Half of the participants were married $(n=5)$ and were living together with their partner (but nobody had to care for his or her partner), whereas four participants were widowed and one was divorced. The education level among the participants was mostly primary school $(n=7)$; the study included two participants who attended secondary school and one who attended high school. Almost all participants $(n=8)$ were members of a club or association. All of them had a car at their disposal. 


\section{Study Design, Procedure and Data Analysis}

Ethical approval for this cross-sectional study, which follows the ethical framework for automated, wearable cameras in health behaviour research (Kelly et al. 2013c), was provided by the Ethical Committee of the University of Education Schwäbisch Gmünd. Recruited participants were fully informed about the goals of the study. After providing informed consent, they were asked to complete a questionnaire related to their demographic backgrounds. Then, the participants were given instructions on how to use the camera. They also received small cards to note the time points for which they would not have images included in the study. Further materials, such as a small instruction book for technical information, were also distributed. Participants were given written instructions and were advised on respecting the autonomy of third parties (e.g., family members or friends), informing others about the study and the camera, seeking their permission and providing them with the opportunity to delete images that they would prefer to not have been taken. It was emphasised that the camera could be removed for any reason if necessary. Participants were asked to wear the camera during waking hours for two consecutive days. After the two days, the participants were given the opportunity to view and delete all the images that they or other people considered to be inappropriate for the study. All wearable devices were initialised on the same laptop, making data collection across devices similarly aligned. After the two days, images were downloaded using the manufacturer-supplied software, saved as a .jpg file and examined using the software Google Picasa. Thereafter, each image was coded twice, with one tag distinguishing among different levels of social participation and one labelling out-of-home-mobility (see variables). The software allows for the annotation of each picture. The amount of time (in minutes) for each category was calculated by noting the time stamp, the capture rate (see below) and the number of pictures by using Microsoft Excel 2011 and IBM SPSS Statistics (version 20). In the next step, the amount of time spent in different levels of social participation and out-of-home mobility was summed. Data analysis was performed for the amount of time (a total of $5580.5 \mathrm{~min}$ ) as a continuous dependent variable. $\mathrm{Chi}^{2}$ tests were conducted using the dichotomous variable out-of-home mobility as an independent factor.

\section{Material}

The Autographer is a small wearable camera $(90 \times 36 \mathrm{~mm}$ in size and approximately $60 \mathrm{~g}$ ). It is worn with a lanyard around the neck. The device facilitates passive image capture from first-person view and records a time stamp but does not record audio. The capture rate was determined to be every $15 \mathrm{~s}$.

\section{Variables}

\section{Social Participation}

The concept of social participation was quantified by relating the camera wearing time to the level of social participation as described above (Levasseur et al. 2010). Therefore, a specific coding scheme was developed. Levasseur et al. (2010) propose three cues concerning (a) the social interaction, (b) the goal and (c) the activities' environment, 
leading to categorisation into one of the six distinct levels of social participation. The first cue, social interaction, helps to differentiate between activities with or without interaction (i.e., level 1 or $2=$ no interaction or levels 3 to $6=$ with interaction). Cue number two (goal) provides information on the goals of activities: being oriented towards basic needs (levels 1 and 2), social interaction (level 3), tasks (level 4), helping others (level 5) and society (level 6). Cue number three (environment of activities) takes into account that specific social activities are associated with social roles, which are in turn determined by the environment (Asendorpf 2007, p. 283), which therefore 'acts' as a tag (Levasseur et al. 2010). Since an activity can be performed alone but oriented towards society, Levasseur and colleagues propose the goal of the activities, rather than the interaction, is crucial for its categorisation. As an example, if a person is situated in a restaurant without having other people around (level 1), the environment 'restaurant' would be seen as socially oriented (level 3). Consequently, this activity would be coded as level 3. Coding a picture as level 5 or level 6 required analysing the pictures according to the environmental information, such as the presence of other people and the behavioural setting (Barker 1968). For instance, pictures were coded as level 6 if the study participant took part at a political club meeting. Different levels of social participation can also occur at home, such as being alone and watching TV (level 1) or gardening with someone else (collaborating to reach the same goal=level 4).

\section{Out-of-Home Mobility}

Engaging in the living environment was operationalised as 'out-of-home mobility', defined as the amount of time spent out of the house (Engstler et al. 2004). Therefore, all the available pictures were coded as 0 or 1 for the home environment and the out-ofhome environment, respectively. To determine the extent of out-of-home mobility, all coded pictures were multiplied by the capture rate of $15 \mathrm{~s}$ (e.g., 20 pictures at $15 \mathrm{~s}$ each equals $300 \mathrm{~s}$ of out-of-home mobility). Following Rosso et al. (2013), two mobility groups - low vs. high mobility - were differentiated. Therefore, an overall score summarises the out-of-home time (in minutes) per person. In a second step, overall individual out-of-home-time was divided by participants' individual camera wear time. This procedure respects possible differences in wear time and leads to a fair-value mobility score per person. Following Rosso et al. (2013), low versus high mobility was determined by being above or below the median for the composite score.

\section{Results}

From the 10 participants, 23072 Autographer images were captured $(M=2307.2 \pm$ 686.7 pictures), which equals $5768 \mathrm{~min}$ or $96.1 \mathrm{~h}$ of wear time across two consecutive investigation days $(M=9.6 \pm 2.7 \mathrm{~h})$. In sum, 750 pictures could not be analysed because they were dark or blurry. Study participants did not ask to exclude pictures from the analysis. Ultimately, $22322(M=2232.2 \pm 687.1)$ valid pictures were identified and included for further analysis, equalling $5580.5 \mathrm{~min}(M=558.0 \pm 171.8)$ of daily activities.

Study participants spent $35.3 \%$ of wear time in level 1 activities (Table 1). Examples of such activities are being alone at home and/or reading a book, mowing the lawn, 
doing the laundry or going for a walk without others being around (see pictures in Appendix Fig. 1). One-fourth of time (25.6\%) was spent in level 2 activities, such as being at the grocery store. Approximately one-fifth $(18.4 \%)$ of the time was spent in level 4 activities (e.g., walking the dog together). Less time was spent in level 3 (15\%, e.g., engaging in brief small talk when meeting other people while strolling about), level 5 (1.5\%; e.g., gardening at someone else's home) and level 6 activities (4.2\%, e.g., taking part in a political club meeting).

Table 2 shows the time participants have been wearing the Autographer as well as the amount of out-of-home time spent engaging in social activities overall and separately for high-mobility and low-mobility participants. Mobility groups differed with respect to the time spent in higher levels of social activities $\left(\mathrm{Chi}^{2}=200,664, \mathrm{df}=5\right.$, $p<.001)$. Low-mobility participants spent most of their out-of-home mobility involved in level 4 activities $(52.39 \%$ ) but did not engage in level 5 or level 6 activities. In contrast, high-mobility older people also spent time in those higher levels of social participation.

\section{Discussion}

This study aimed to investigate the social participation and out-of-home mobility of older people using a picture-based ambulatory assessment method. Participants spent most of their time in activities with no interaction (level 1: being alone and level 2: being alone but having others around), which is consistent with the findings of other studies, showing that older adults spent most of their daytime alone (Chilvers et al. 2010; McKenna et al. 2007). The comparison of time spent in level 3 (interacting with others) and level 4 (engaging in activities collaboratively) reveals that our study participants are more task-oriented and spent less time on level 3 activities (social interactions). They are also slightly more engaged in societal activities (level 6) than in helping others (level 5). Moreover, the results of our study suggest that more time spent out of the home (high mobility) is associated with spending more time in higher levels of social participation, such as helping other people (level 5) or contributing to society (level 6). This finding is also consistent with those of previous studies (e.g., Rosso et al. 2013; Tivig and Kasch 2015), which noted that the physical environment as well as neighbourhood and social factors may support older adults' physical activity (Chaudhury et al. 2016) and therefore their ability to stay in touch with others and to engage in meaningful activities (e.g., Lewicka 2011). Furthermore, being involved in group activities or associations has been identified as a factor facilitating physical activity as well as increasing social interaction through walking groups or similar concepts (Belon et al. 2014). As Carver et al. (2018) reviewed, being with others, interacting socially, engaging in activities with others and being mobile play a crucial role in older people's lives. Our study puts these pieces together and shows that in our sample, being out of the home enhances the likelihood of experiencing higher levels of social participation.

An advantage of applying picture-based ambulatory assessment methods is that they lead to the collection of information and data with high ecological validity and context specificity (Fahrenberg et al. 2007), partly due to the information being collected from the first-person perspective at the time of exposure (Oliver et al. 2013) and the 


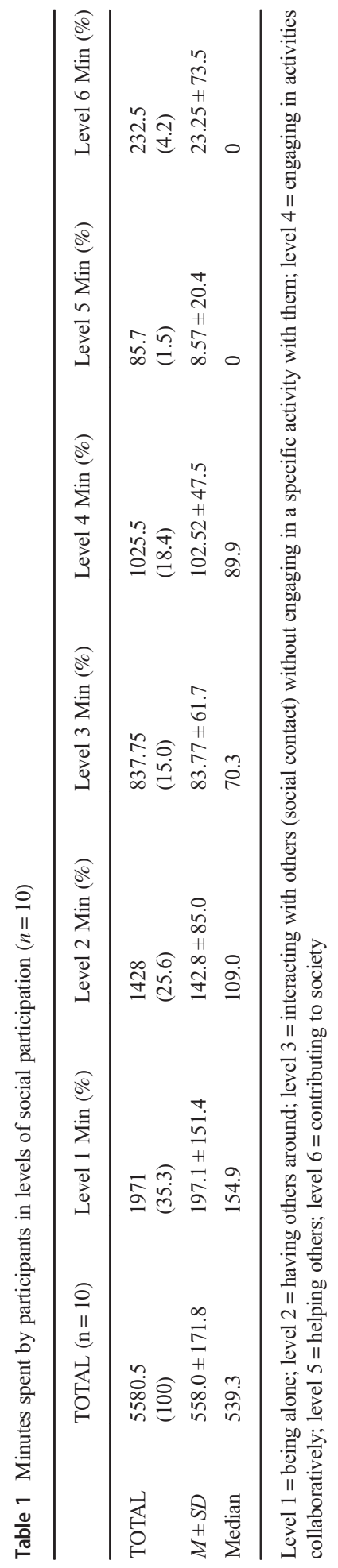


Table 2 Wear time and minutes spent engaged in out-of-home mobility according to the level of social participation for all study participants as well as separated for high- and low-mobility participants

\begin{tabular}{llll}
\hline & TOTAL Min. $(\%)$ & $\begin{array}{l}\text { High mobility } \\
(n=5) \text { Min. }(\%)\end{array}$ & $\begin{array}{l}\text { Low mobility } \\
(\mathrm{n}=5) \text { Min. (\%) }\end{array}$ \\
\hline $\begin{array}{l}\text { Wear time } \\
\text { Out-of-home-mobility time }\end{array}$ & $5768.0(100)$ & $2417.8(41.9)$ & $3350.3(58.1)$ \\
Social participation: & $2239.7(100)$ & $1496.7(66.8)$ & $742.00(33.2)$ \\
Level 1 & $224.5(10.0)$ & $172.0(11.5)$ & $52.5(7.1)$ \\
Level 2 & $556.5(24.8)$ & $380.5(25.4)$ & $176.0(23.7)$ \\
Level 3 & $339.8(15.2)$ & $214.5(14.3)$ & $125.3(16.96)$ \\
Level 4 & $856.8(38.3)$ & $467.5(31.2)$ & $389.3(52.4)$ \\
Level 5 & $30.5(1.4)$ & $30.5(2.0)$ & $0(0)$ \\
Level 6 & $231.8(10.4)$ & $231.8(15.5)$ & $0(0)$ \\
\hline
\end{tabular}

Level 1 = being alone; level 2 = having others around; level 3 = interacting with others (social contact) without engaging in a specific activity with them; level $4=$ engaging in activities collaboratively; level $5=$ helping others; level $6=$ contributing to society

collection of multiple pieces of information, such as information about the level of social participation, the setting or place where a given situation occurs (Anonymous 2016). Passively taken pictures may also reduce study participants' workload, since they replace (parts of) self-administered questionnaires or interviews, which may lead to data affected by recall bias.

However, there are also shortcomings and issues that should be considered. First, assessment duration was determined on two consecutive days, which limits the representativeness of the participants' activities. Therefore, the images of our study hardly captured all association activities, even though a large proportion of the rural population may participate there (Koch 2012). The photo-based ambulatory assessment also has shortcomings with respect to specific aspects of social participation. For instance, forms of interactions that are not visible from a firstperson perspective, such as communicating via telephone, are difficult to assess. Furthermore, in a study by Naumann (2006), older people reported on "knowing what is going on in the neighbourhood" (p. 196). Oswald and Konopik (2015) found that such "knowings" - which are not detectable by camera pictures - are relevant to individuals' well-being, especially in older age. Another point to consider is the given study design, which does not provide information about causality between out-of-home mobility and social participation. Consequently, it is not clear whether the study participants experienced more social activities due to being more mobile or vice versa. However, the description of the levels of social experience of the participants separated by low versus high out-of-home mobility follows common assumptions of socio-ecological models (Glass and McAtee 2006) and approaches from environmental gerontology (Rowles and Bernard 2013; Wahl et al. 2012). Furthermore, applying this method is a matter of financial resources. The sample size and the study duration may be restricted due to the number of available devices. Furthermore, the large number of captured 
images requires time to examine and analyse. For these reasons, the given pilot study involves ten people, and the results represent their daily lives, which might be specific and could differ in studies with, for instance, other people or other inclusion criteria. Thus, the results lack representativeness, although a large amount of data were analysed (approximately 23000 pictures). Nevertheless, some colleagues have tried to overcome this restriction by merging similar images automatically into 'events' (Doherty et al. 2012) or proposing special techniques to identify events in a set of pictures (Doherty et al. 2013b).

Subject compliance or dark images due to incorrect camera positioning are further typical challenges (Doherty et al. 2013a). Due to the detailed introduction about the functioning of the wearable cameras and the provision of additional participant material, we had a modicum of indeterminable images. Another problem concerned invisible cues of information of the images, which did not cover the activities' whole environment. For instance, mowing the lawn for another person would be considered as a level 5 activity (helping others). However, if there is no hint of others being around, it could also be considered as a level 1 activity (no interaction with others). Therefore, this study prioritises the goal of the activities (e.g., oriented towards helping others) and not the actual performance (e.g., being alone or interacting with others), which in some cases determines the level of social participation.

It should be noted that conducting picture-based studies also has ethical implications (Kelly et al. 2013) concerning the privacy or confidentiality of study participants themselves as well as that of other people. Image capturing may be unbidden or unflattering. Other people who are not directly involved as study participants may not be aware of being more or less part of a study or may claim the right to their own pictures. The given study therefore followed Kelly and colleagues' ethical framework (Kelly et al. 2013), which should be mandatory for all further studies using automated wearable cameras.

\section{Conclusion and Implications}

Detailed information about older people's level of social participation as well as their out-of-home mobility can be identified by applying picture-based ambulatory assessment. This is crucial, since the first outcome is a sophisticated construct, and both variables are often difficult to remember and therefore difficult to assess. First-person perspective pictures provide multiple pieces of information with high ecological validity. This method and studies such as ours might be useful in the investigation of (older) people's behaviour, such as their social participation. Further studies might focus on getting older people out of their homes, for instance, by investigating aspects of "age-friendly environments" (Scharlach 2017).

\section{Acknowledgements Open Access funding provided by Projekt DEAL.}

\section{Compliance with Ethical Standards}

Conflict of Interest The authors declare that they have no conflict of interest.

Ethical Approval Ethical approval was obtained and all study participants provided informed consent. 


\section{Appendix}

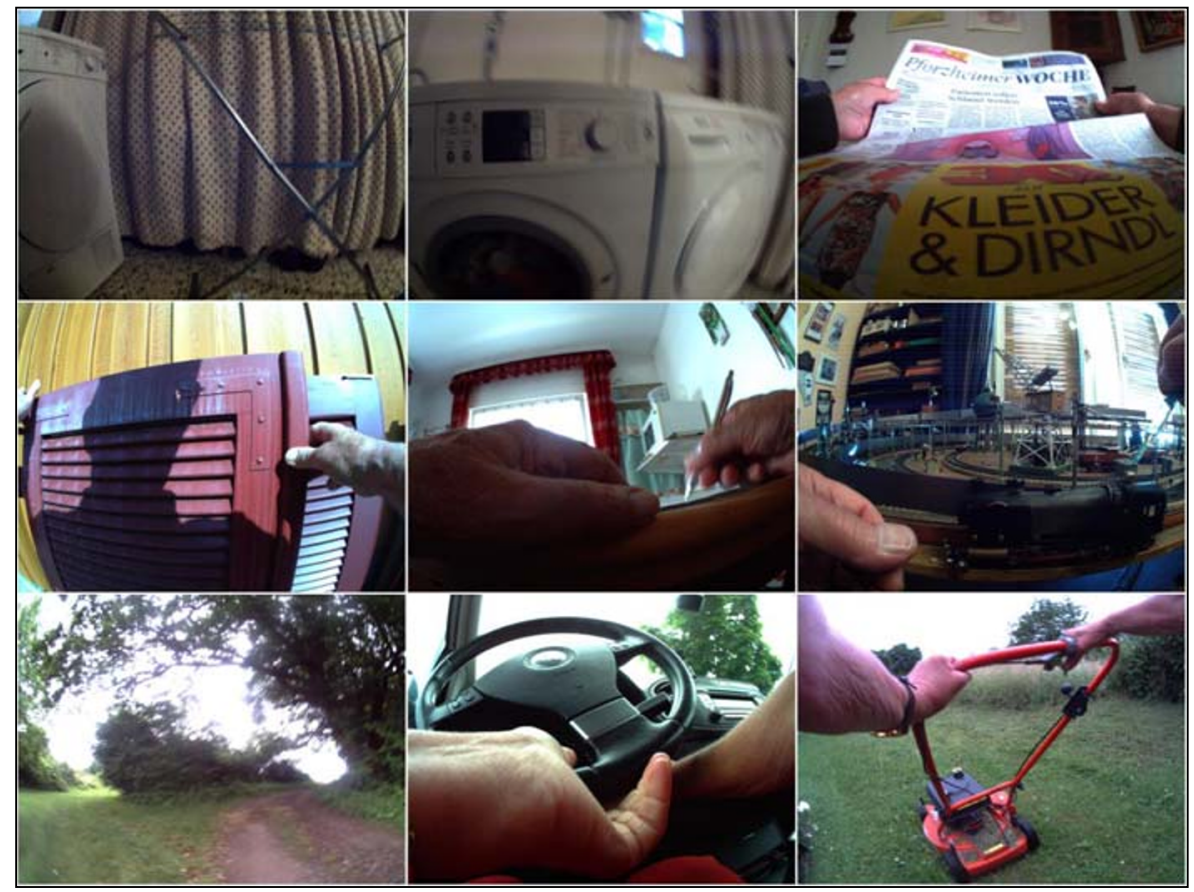

Fig. 1 Selected pictures of activities participants spent in level 1

Open Access This article is licensed under a Creative Commons Attribution 4.0 International License, which permits use, sharing, adaptation, distribution and reproduction in any medium or format, as long as you give appropriate credit to the original author(s) and the source, provide a link to the Creative Commons licence, and indicate if changes were made. The images or other third party material in this article are included in the article's Creative Commons licence, unless indicated otherwise in a credit line to the material. If material is not included in the article's Creative Commons licence and your intended use is not permitted by statutory regulation or exceeds the permitted use, you will need to obtain permission directly from the copyright holder. To view a copy of this licence, visit http://creativecommons.org/licenses/by/4.0/.

\section{References}

Annear, M., Keeling, S., Wilkinson, T., Cushman, G., Gidlow, B., \& Hopkins, H. (2014). Environmental influences on healthy and active ageing: A systematic review. Ageing \& Society, 34, 590-622.

Anonymous, (2016). Details omitted for double-blind reviewing.

Asendorpf, J.B. (2007). Psychologie der Persönlichkeit [Psychology of personality] (4., revised and updated edition). Springer Medizin, Heidelberg.

Baker, P. S., Bodner, E. V., \& Allman, R. M. (2003). Measuring life-space mobility in community-dwelling older adults. Journal of the American Geriatrics Society, 51, 1610-1614.

Barker, R. G. (1968). Ecological psychology. Stanford: Stanford University Press.

Bathgate, T., \& Romios, P. (2011). Consumer participation in health: Understanding consumers as social participants. Institute for Social Participation and Health Issues Centre, La Trobe University.

Baum, F., \& Palmer, C. (2002). "Opportunity structures": Urban landscape, social capital and health promotion in Australia. Health Promotion International, 17, 351-361. 
Bauman, A., Merom, D., Bull, F. C., Buchner, D. M., \& Singh, M. A. F. (2016). Updating the evidence for physical activity: Summative reviews of the epidemiological evidence, prevalence, and interventions to promote "active aging". The Gerontologist, 56, 268-280.

Belon, A. P., Nieuwendyk, L. M., Vallianatos, H., \& Nykiforuk, C. I. J. (2014). How community environment shapes physical activity: Perceptions revealed through the PhotoVoice method. Social Science \& Medicine, 116, 10-21.

Brusilovski, E., Klein, L. A., \& Salzer, M. S. (2016). Using global positioning systems to study health-related mobility and participation. Social Science \& Medicine, 161, 134-142.

Buffel, T., Donder, L., Phillipson, C., Dury, S., de Witte, N., \& Verte, D. (2013). Social participation among older adults living in medium-sized cities in Belgium: The role of neighbourhood perceptions. Health Promotion International. https://doi.org/10.1093/heapro/dat009.

Burholt, V., Winter, B., Aartsen, M., Constantinou, C., Dahlberg, L., Feliciano, V., De Jong Gierveld, J., Van Regenmortel, S., \& Feliciano, V. (2019). A critical review and development of a conceptual model of exclusion from social relations for older people. European Journal of Ageing., 17, 3-19. https://doi. org/10.1007/s10433-019-00506-0.

Carver, L. F., Beamish, R., Phillips, S. P., \& Villeneuve, M. (2018). A scoping review: Social participation as a cornerstone of successful aging in place among rural older adults. Geriatrics, 3, 75. https://doi. org/10.3390/geriatrics3040075.

Chaudhury, H., Campo, M., Michael, Y., \& Mahmood, A. (2016). Neighborhood environment and physical activity in older adults. Social Science \& Medicine, 149, 104-113.

Chilvers, R., Corr, S., \& Singlehurst, H. (2010). Investigation into the occupational lives of healthy older people through their use of time. Australian Occupational Therapy Journal, 57, 24-33.

Claßen, K., Oswald, F., Doh, M., Kleinemas, U., \& Wahl, H.-W. (2014). Umwelten des Alterns: Wohnen, Mobilität, Technik und Medien [Environments of Ageing: Housing, Mobility, Technology and Media]. Stuttgart: Kohlhammer.

DiPietro, L. (2001). Physical activity in aging: Changes in patterns and their relationship to health and function. The Journals of Gerontology, 56, 13-22.

Doherty, A., Pauly-Takacs, K., Caprani, N., Gurrin, C., Moulin, C., O’Connor, N., \& Smeaton, A. (2012). Experience of aiding autobiographical memory using the SenseCam. Human Computing International, 27, 151-174.

Doherty, A. R., Hodges, S. E., King, A. C., Smeaton, A. F., Berry, E., Moulin, C. J. A., Lindley, S., Kelly, P., \& Foster, C. (2013a). Wearable cameras in health. The state of the art and future possibilities. American Journal of Preventive Medicine, 44, 320-323.

Doherty, A., Kelly, P., \& Foster, C. (2013b). Wearable cameras: Identifying healthy transportation choices. Pervasive Computing, 12, 44-47.

Doherty, A., Kelly, P., Kerr, J., Marshall, S., Oliver, M., Badland, H., Hamilton, A., \& Foster, C. (2013c). Using wearable cameras to categorise type and context of accelerometer-identified episodes of physical activity. International Journal of Behavioural Nutrion and Physical Activity, 10, 22.

Engstler, H., Menning, S., Hoffmann, E., \& Tesch-Römer, C. (2004). Die Zeitverwendung älterer Menschen [Time-patterns of older people]. In: Statistisches Bundesamt (ed) Alltag in Deutschland: Analysen zur Zeitverwendung. pp 216-246 Beiträge zur Ergebniskonferenz der Zeitbudgeterhebung 2001/02 am 16./ 17. Februar 2004 in Wiesbaden. Forum der Bundesstatistik (43).

Fahrenberg, J., Myrtek, M., Pawlik, K., \& Perrez, M. (2007). Ambulatory assessment. Monitoring behaviour in daily life settings. A behavioural-scientific challenge for psychology. European Journal of Psychological Assessment, 23, 206-213.

Faß, E., \& Schlesinger, T. (2019). The relation of physical activity and self-rated health in older age - Cross country analysis results from SHARE. Population Ageing. https://doi.org/10.1007/s12062-019-09242-w.

Glass, T. A., \& McAtee, M. J. (2006). Behavioural science at the crossroads in public health: Extending horizons, envisioning the future. Social Science \& Medicine, 62, 1650-1671.

Gracia, E., \& Herrero, J. (2004). Determinants of social integration in the community: An exploratory analysis of personal, interpersonal and situational variables. Journal of Community \& Applied Social Psychology, 14, 1-15.

Hamer, M., de Oliveira, C., \& Demakakos, P. (2014). Non-exercise physical activity and survival. English longitudinal study of ageing. American Journal of Preventive Medicine, 47, 452-460.

Hodge, A. M., English, D. R., Giles, G. G., \& Flicker, L. (2013). Social connectedness and predictors of successful ageing. Maturitas, 75, 361-366.

Hwang Han, S., Tavares, J. L., Evans, M., Saczynski, J., \& Burr, J. A. (2017). Social activities, incident cardiovascular disease, and mortality. Journal of Aging \& Health, 29, 268-288.

Kelly, P., Doherty, A., Berry, E., Hodges, S., Batterham, A. M., \& Foster, C. (2011). Can we use digital life-log images to investigate active and sedentary travel behaviour? Results from a pilot study. International Journal of Behavioural Nutrition and Physical Activity, 8, 44. 
Kelly, P., Marshall, S., Badland, H., Kerr, J., Oliver, M., Doherty, A., \& Foster, C. (2013). An ethical framework for automated, wearable cameras in health behaviour research. American Journal of Preventive Medicine, 44, 314-319.

Kelly, P., Doherty, A., Mizdrak, A., Marshall, S., Kerr, J., Legge, A., Godbole, S., Badland, H., Oliver, M., \& Foster, C. (2014). High group level but high random error of self-report travel diary, as assessed by wearable cameras. Journal of Transport \& Health, 1, 190-201.

Kelly, P., Thomas, E., Doherty, A., Harms, T., Burke, O., Gershuny, J., \& Foster, C. (2015). Developing a method to test the validity of 24-hour time use diaries using wearable cameras: A feasibility pilot. PLoS One, 10.

Koch, S. (2012). Nachhaltige Dorfentwicklung. Zukunft - Identität - Tradition in nord- hessischen Dörfern [Sustained rural development. Future - Identity and tradition]. Kassel: Kassel University Press.

Koster, M., Nakken, H., Pijl, S. J., \& van Houten, E. (2009). Being part of the peer group: A literature study focusing on the social dimension of inclusion in education. International Journal of Inclusive Education, $13,117-140$.

Lampinen, P., \& Heikkinen, E. (2003). Reduced mobility and physical activity as predictors of depressive symptoms among community-dwelling older adults: An eight-year follow-up study. Aging Clinical \& Experimental Research, 15, 205-211.

Lefrancois, R., Leclerc, G., Dube, M., Hamel, S., \& Gaulin, P. (2001). Valued activities of everyday life among the very old: A one-year trend. Activities, Adaptation \& Aging, 25, 19-35.

Levasseur, M., Richard, L., Gauvin, L., \& Raymond, E. (2010). Inventory and analysis of definitions of social participation found in the aging literature: Proposed taxonomy of social activities. Social Science \& Medicine, 71, 2141-2149.

Lewicka, M. (2011). Place attachment: How far have we come in the last 40 years? Journal of Environmental Psychology, 31, 207-230.

Macintyre, S., \& Ellaway, A. (1999). Local opportunity structures, social capital and social inequalities in health: What can central and local government do? Health Promotion Journal of Australia, 9, 165-170.

Maier, H., \& Klumb, P. L. (2005). Social participation and survival at older ages: Is the effect driven by activity content or context? European Journal of Ageing, 2, 31-39.

McKenna, K., Broome, K., \& Liddle, J. (2007). What older people do: Time use and exploring the link between role participation and life satisfaction in people aged 65 years and over. Australian Occupational Therapy Journal, 54, 273-284.

Miceli, S., Maniscalco, L., \& Matranga, D. (2018). Social networks and social activities promote cognitive functioning in both concurrent and üprospective time: Evidence from the share servey. European Journal of Ageing. https://doi.org/10.1007/s10433-018-0486-z.

Naumann, D. (2006). Gesellschaftliche integration und Mitwirkung im Kontext des hohen Alters [Integration and participation in the community in advanced old age]. Dissertation, University of Heidelberg.

Regionalverband Nordschwarzwald (2007). Regionalplan 2015 Nordschwarzwald [Regional development plan 2015 Nordschwarzwald]. Pforzheim.

Oliver, M., Doherty, A., Kelly, P., Badland, H., Mavoa, S., Shepherd, J., Kerr, J., Marshall, S., Hamilton, A., \& Foster, C. (2013). Utility of passive photography to objectively audit built environment features of active transport journeys: An observational study. International Journal of Health Geography, 12, 20.

Oswald, F., \& Konopik, N. (2015). Bedeutung von außerhäuslichen Aktivitäten, Nachbarschaft und Stadtteilidentifikation für das Wohlbefinden im Alter [Impact of out-of-home activities, neighborhood and urban-related identity on well-being in old age]. Zeitschrift für Gerontololgie \& Geriatrie, 48, 401-407.

Piskur, B., Daniëls, R., Jongmans, M. J., Ketelaar, M., Smeets, R. J., Norton, M., \& Beurskens, A. J. (2014). Participation and social participation: Are they distinct concepts? Clinical Rehabilitation, 28, 211-220.

Putnam, R. D. (2000). Bowling alone. The collaps and revival of American community. New York: Simon \& Shuster.

Pynnönen, K., Törmäkangas, T., Rantanen, T., \& Lyyra, T.-M. (2014). Do mobility, cognitive functioning, and depressive symptoms mediate the association between social activities and mortality risk among older men and women? European Journal of Ageing, 11, 121-130.

Richard, L., Gauvin, L., Kestens, Y., Shatenstein, B., Payette, H., Daniel, M., Moore, S., Levasseur, M., \& Mercille, G. (2013). Neighborhood resources and social participation among older adults. Journal of Aging \& Health, 25, 296-318.

Rosso, A. L., Taylor, J. A., Tabb, L. P., \& Michael, Y. L. (2013). Mobility, disability and social engagement in older adults. Journal of Aging \& Health, 25, 617-637.

Rowe, J. W., \& Kahn, R. L. (1997). Successful Aging. Gerontologist, 37, 433-440.

Rowles, G. D., \& Bernard, M. (2013). The meaning and significance of place in old age. In G. D. Rowles \& M. Bernard (Eds.), Environmental gerontology. Making meaningful places in old age (pp. 4-24). New York: Springer.

Rubinstein, R. L. (1989). The home environments of older people: A description of the psychosocial processes linking person to place. Journal of Gerontology, 44, 45-53. 
Sallis, J. F., Cervero, R. B., Ascher, W., Henderson, K. A., Kraft, M. K., \& Kerr, J. (2006). An ecological approach to creating active living communities. Annual Reviews of Public Health, 27, 297-322.

Sawyer, A., Ucci, M., Jones, R., Smith, L., \& Fisher, A. (2018). Supportive environments for physical activity in deprived communities in the United Kingdom: A qualitative study using photo elicitation. Social Science \& Medicine, 197, 49-58.

Scharlach, A. E. (2017). Ageing in context: Individual and environmental pathways to aging-friendly communities - The 2015 Matthew A. Pollack award lecture. Gerontologist, 57, 606-618.

Schlicht, W. (2017). Urban health. Wiesbaden: Springer Spektrum.

Schlicht, W., \& Oswald, F. (2018). Soziale und räumlich-dingliche Umwelt als Determinante körperlicher Aktivität in Alternskonzepten. [Social and physical environments as determinant of physical activity in concepts of aging]. In U. Granacher, H. Mechling, \& C. Voeckler-Rehage (Eds.), Bewegungs- und Sportgerontologie [Gerontology of movement science] (pp. 127-140). Schorndorf: Hofmann.

Schlicht, W., Ebner-Priemer, U., \& Kanning, M. (2013). Ecological momentary assessment and intervention in physical activity and well-being: Affective reactions, social-cognitive factors, and behaviours as determinants of physical activity and exercise. Frontiers in Psychology, 4, 916.

Schott, N. (2007). Korrelate der Sturzangst im Alter [Correlates of fear of falls in older age]. Zeitschrift für Sportpsychologie, 14, 74-86.

Takemoto, M., Carlson, J. A., Moran, K., Godbole, S., Crist, K., \& Kerr, J. (2015). Relationship between objectively measured transportation behaviours and health characteristics in older adults. International Journal of Environmental Research \& Public Health, 12, 13923-13937.

Thomas, P. A. (2012). Trajectories of social engagement and mortality in late life. Journal of Aging \& Health, $24,547-568$.

Tivig, T., \& Kasch, S. (2015). Außerhäusliche Aktivitäten als Maß für Mobilität und Teilhabe [Out-of-home mobility as indicator for mobility and participation]. Working-Paper 141 der Thünen-Series of applied economic theory.

Tomaka, J., Thompson, S., \& Palacios, R. (2006). The relation of social isolation, loneliness, and social support to disease outcomes among the elderly. Journal of Aging \& Health, 18, 359-384.

Tomaszewski, W. (2013). Living environment, social participation and wellbeing in older age: The relevance of housing and local area disadvantage. Population Ageing, 6, 119-156. https://doi.org/10.1007/s12062012-9077-5.

Trull, T. J., \& Ebner-Priemer, U. (2013). Ambulatory assessment. Annual Reviews of Clinical Psychology, 9, $151-176$.

Wahl, H.-W., Iwarsson, S., \& Oswald, F. (2012). Aging well and the environment: Toward an integrative model and research agenda for the future. Gerontologist, 52, 306-316.

Wang, P., \& Smeaton, A. F. (2013). Using visual lifelogs to automatically characterize everyday activities. Information Science, 230, 147-161.

WBGU. (2016). Der Umzug der Menschheit. Die transformative Kraft der Städte [Moving people. The power of cities]. Berlin: WBGU.

Weideman, S., \& Anderson, J. R. (1985). A conceptual framework for residential satisfaction. In I. Altman \& C. M. Werner (Eds.), Human behavior and environment, Vol. 8: Home environments (pp. 153-182). New York: Plenum Press.

Publisher's Note Springer Nature remains neutral with regard to jurisdictional claims in published maps and institutional affiliations.

\section{Affiliations}

\section{Daniela Kahlert ${ }^{1} \cdot$ Niklas Ehrhardt $^{2}$}

1 Department of Health Science, University of Education Schwäbisch Gmünd, Oberbettringer Str. 200, Schwäbisch Gmünd, Germany

2 Department for Sport and Movement Science, University of Stuttgart, Allmandring 28, Stuttgart, Germany 